
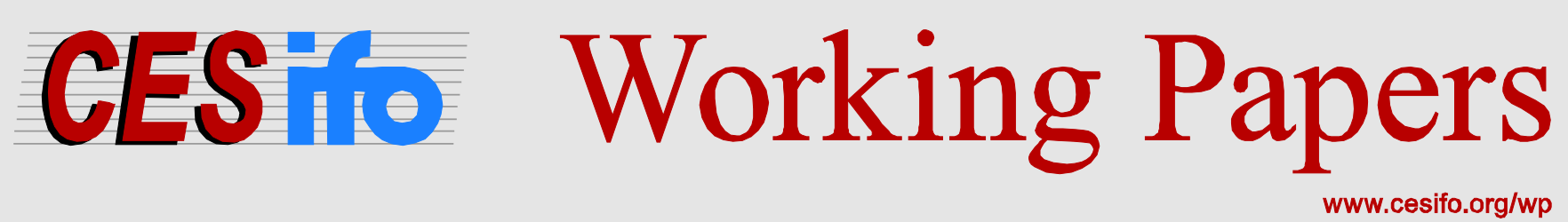

\title{
At the Very Edge of a Storm: The Impact of a Distant Cyclone on Atoll Islands
}

\author{
Tauisi Taupo \\ Ilan Noy
}

\author{
CESIFO WORKING PAPER NO. 6220 \\ CATEGORY 10: ENERGY AND CLIMATE ECONOMICS \\ NOVEMBER 2016
}

An electronic version of the paper may be downloaded

- from the SSRN website:

- from the RePEc website:

- from the CESifo website:

wWw.SSRN.com

www.RePEc.org

www.CESifo-group.org/wp

\section{CESifo}




\title{
At the Very Edge of a Storm: The Impact of a Distant Cyclone on Atoll Islands
}

\begin{abstract}
The intensity of cyclones in the Pacific is predicted to increase and sea levels are predicted to rise, so an atoll nation like Tuvalu can serve as the 'canary in the mine' pointing to the new risks that are emerging because of climatic change. Based on a household survey we conducted in Tuvalu, we quantify the impacts of Tropical Cyclone Pam (March 2015) on households, and the determinants of these impacts in terms of hazard, exposure, vulnerability and responsiveness. Households experienced significant damage due to the storm surge caused by the cyclone, even if the cyclone itself passed very far away (about a $1000 \mathrm{~km}$ ). This risk of distant cyclones has been overlooked in the literature, and ignoring it leads to significant under-estimation of the disaster risk facing low-lying atoll islands. Lastly, we constructed hypothetical policy scenarios, and calculated the estimated loss and damage they would have been associated with - a first step in building careful assessments of the feasibility of various disaster risk reduction policies.
\end{abstract}

Keywords: cyclone, Tuvalu, impact.

Tauisi Taupo

School of Economics and Finance

Victoria University of Wellington

PO Box 600

New Zealand - 6140 Wellington

tauisi.taupo@uw.ac.nz
Ilan Noy

School of Economics and Finance

Victoria University of Wellington

PO Box 600

New Zealand - 6140 Wellington

ilan.noy@vuw.ac.nz

November 2016 


\section{At the Very Edge of a Storm: The Impact of a Distant Cyclone on Atoll Islands}

\section{Introduction}

Among the Small Island Developing States (SIDS) in the Pacific, Tuvalu consists of nine lowlying atoll islands spread over a large expanse of ocean. Tuvalu is likely one of the most vulnerable countries to disasters in per capita terms; and is particularly vulnerable to destructive cyclones with their associated storm surges and flooding. ${ }^{1}$ Changes in weather patterns and the threat of rising sea levels further aggravate these threats. An underappreciated and insufficiently modelled risk facing Tuvalu is storm surges generated by distant storms. This is the focus of this paper.

Briguglio (1997), Intergovernmental Panel on Climate Change (2014) and the World Bank (2014) recognized the vulnerability of SIDS to disasters and the lack of economic resilience arising from the relative inability of these countries to face forces of these magnitudes. Christenson et al. (2014) found out that in their estimations of population exposed to cyclones, more than half of the top 20 countries world-wide are from the SIDS.

Tuvalu is extremely vulnerable to disasters, even by SIDS standards, due to its small geographical size, insularity and exceptional remoteness, the concentration of economic activities and settlements along low-lying coastal areas, the narrow width of islands, the very limited natural resource base, a heavy reliance on subsistence agriculture and inadequate disaster mitigation capabilities. The Emergency Events Database (EM-DAT) recorded only four storms that affected Tuvalu from 1900 to 2016: the 1972 Tropical Cyclone Bebe, 1990, 1993, and the recent 2015 Tropical Cyclone (TC) Pam. Bebe in 1972 struck down $90 \%$ of the houses and killed six people. The other publicly available database of disaster impacts - DesInventar, in contrast, lists tropical cyclones that hit Tuvalu in 1959, 1965, 1972, 1984, 1987, 1990, 1992, 1993 (twice), 1997 (twice), and 2015. Both datasets underestimate disaster damages for Tuvalu for a variety of reasons (see Noy, 2016, for details). An analysis of the 2010 Household Income \& Expenditure Survey (HIES) shows that a large proportion of poor households reside near areas prone to cyclone surges (Taupo, Cuffe, \& Noy, 2016).

Recently, both TC Pam and Ula in 2015 re-focused attention on the vulnerability of Tuvalu to cyclones after a benign period of 18 years. TC Pam appeared on the world's radar screens on March $6^{\text {th }}$, but became a full blown category $V$ cyclone on March $12^{\text {th }}$. In the two days previous to that date, it was not moving very fast, but generated a significant storm surge that hit the outer islands of Tuvalu; peaking on March $11^{\text {th }}$ (see map in Figure 1). Although TC Pam's centre passed over 1000 kilometers away from Tuvalu, Tuvaluans found themselves significantly affected by the storm surge the cyclone generated. According to our calculations based on the survey described below, Tuvaluans suffered huge monetary losses amounting to almost $10 \%$ of GDP due to damages to properties, appliances and assets, loss to plantations and livestock, and to infrastructure. ${ }^{2}$ 
Here, we examine the experience of Tuvalu with TC Pam. Since most of the low-income households reside in high-risk areas with minimal capacity to prepare and respond to climate disasters, we pay special attention to them. The main focus of this paper is to enrich our understanding of vulnerability, exposure, and responsiveness to cyclones for the residents of SIDS, particularly to distant cyclones and atoll SIDS. ${ }^{3}$

For that purpose, we first describe the results of the post-Pam household survey we conducted, and estimate the determinants of damage and loss associate with the cyclone. We then calculate the estimated damage with hypothetical scenarios accounting for reduced (or increased) vulnerability, exposure, and responsiveness. We end with some policy implications.

\section{The Literature on Disaster Risk}

There is an extensive literature, from various disciplines, covering the concepts of vulnerability and resilience with respect to natural hazards. An offspring from multiple conceptual frameworks is the now widely used framework whereby risk is a multiplicative function of hazard, exposure and vulnerability. ${ }^{4}$

Akter and Mallick (2013) examine the impacts of a cyclone in Bangladesh, and show the negative impacts of the cyclone on income, employment and access to clean water and sanitation. Smith and Rhiney (2015) and Lopez-Marrero and Wisner (2012) stress that vulnerability to negative impacts of climate risk is partly a function of the differential coping and adapting capabilities of various groups of people. They further point out that vulnerability to climatic impacts is inherently developmental as the differentiated levels of exposure and sensitivity to natural hazards are partly created by basic social and economic inequalities, and accessibility to resources, assets and government support. ${ }^{5}$

Field et al. (2014) defines Risk as the "potential for consequences where something of value is at stake and where the outcome is uncertain, recognizing the diversity of values. It is often represented as the probability of occurrence of hazardous events"; Hazard refers to the "potential occurrence of a natural or human-induced physical event or trend or physical impact that may cause loss of life, injury, or other health impacts, as well as damage and loss to property, infrastructure, livelihoods, service provision, ecosystems, and environment resources"; Exposure is the "presence of people, livelihoods, species or ecosystems, environmental functions, services, and resources, infrastructure, or economic, social, or cultural assets in places and settings that could be adversely affected"; and Vulnerability is define as the "propensity of predisposition to be adversely affected...including sensitivity or susceptibility to harm and lack of capacity to cope and adapt" (Cavallo \& Noy, 2011; Noy, 2016; Taupo et al., 2016; Yonson, Gaillard, \& Noy, 2016; World Bank \& GFDRR, 2013; UNISDR, 2009; United Nations, 2015; Wisner, Gaillard, \& Kelman, 2011; Wisner, Blaikie, Cannon, \& Davis, 2003) 
In our analysis, a disaster leads to (ex post) impact, which can similarly to risk be expressed as: Impact $=$ Vulnerability $\times$ Exposure $\times$ Hazard $\times$ Responsiveness. This empirical study of the impact of a tropical cyclone at the household level is the first to provide empirical observational evidence based on survey data on the consequences of a cyclone on low-lying atoll islands.

Our data on actual disaster damages at the household level are unique, and they enable us to estimate the role of vulnerability, exposure, hazard and responsiveness at the microeconomic level, rather than at the macro-aggregate level as was previously done. This further enables us to estimate the likely impact various policies would have on disaster risk were they to be implemented. Besides our methodological contribution, our paper is also the first, as far as we are aware, that investigates quantitatively the impact of cyclones on atoll islands.

\section{Estimation Method and Survey Data}

In general, we estimated a regression to determine the relationship between disaster impact and vulnerability, exposure, hazard, and responsiveness where we use a conventional cross-sectional sample of $n$ independent observations of households (denoted i) from the survey we conducted after the cyclone (where $i=1, \ldots, n$ ). The observations for loss and damage are linearly conditional on a set of explanatory independent variables as in:

$$
L D_{i}=\alpha+\beta_{v} V u l_{i}+\beta_{e} \operatorname{Exp}_{i}+\beta_{h} \operatorname{Haz}_{i}+\beta_{r} \operatorname{Res}_{i}+\varepsilon_{i}
$$

$L D_{i}$ is the total loss and damage experienced by household $i$, summed up from the survey responses on all the specific loss and damage items. $V u l_{i}, \operatorname{Exp}_{i}, \operatorname{Haz}_{i}, \operatorname{Res}_{i}$ are vectors of independent variables, derived from the survey responses or the household location, and described as measuring vulnerability, exposure, hazard and response. The $\beta$ vectors are the vectors of estimated coefficients describing the partial correlation between these measures and loss and damage per household. The estimated regression also includes a constant $(\alpha)$ and an iid error term $\left(\varepsilon_{i}\right)$.

Vulnerability is a vector of household characteristics that measure household vulnerability to the cyclone; Exposure is a vector measuring the extent of household exposure to TC Pam based on their geo-location; Hazard is a vector of the distance of the cyclone path that indicates the strength of the storm hazard that households experienced; and Responsiveness $_{i}$ is a vector that measures the ability of households to respond or react to TC Pam. All of this data is collected from responses to questions and from the households geolocation as recorded when conducting the survey.

We carried out a detailed household survey from November 2015 to January 2016 in the five islands that were affected by Tropical Cyclone Pam in March $2015 .{ }^{6}$ The survey includes administered interviews to 321 households from 14 different villages representing $58 \%$ of the total number of households in the affected islands. The interviewed households were 
randomly selected following a procedure followed by the Tuvalu Central Statistics Division. ${ }^{7}$ The questionnaire was translated to the Tuvaluan language. ${ }^{8}$ Detailed information was obtained on losses and damages to households; see Table 1.

There is no common definition nor a widely-agreed method for calculating loss and damage. Here, similarly to ECLAC (2014), loss and damages are aggregated the household level and are proxied by the estimated replacement/reconstruction costs for damages to properties and assets, and the estimated income losses due to livestock and crop losses. There was no loss of human lives from the TC Pam, nor much evidence of increased morbidity.

The hazard itself, TC Pam, passed far away from Tuvalu, but the storm surge and heavy rainfall led to flooding and wave damage. Since the storm's centre passed far away, the exact direction of each household relative to the storm's circular movement is not materially important. As a proxy for the strength of the cyclone we focus on measuring the distance of each household from the cyclone path.

For our measure of exposure to the cyclone, we measured the distance to the coastline and the household's elevation above sea-level. Following much of the literature, vulnerability is proxied by income per person, household size, and the strength of the house (whether it is made of cement or wood). The ability to react and respond positively in preparation for the cyclone is potentially effective in lessening the impact of the disaster. Our binary proxy indicators for responsiveness are whether the house was strengthened in preparation for the cyclone, whether the household head received cyclone response capacity training, and whether the household received timely cyclone warning.

\section{Analysis of Survey Responses}

\subsection{Household Characteristics}

We first asked about the household details and characteristics before elaborating on the impact of the TC Pam. About $60 \%$ of families have a gas stove, refrigerator, and a motorcycle (see Figure 2). More expensive durables such as air conditioners are owned by almost no one given the low monthly cash incomes for most households. Most families live in houses that are more than 20 years old. $83 \%$ of houses are made of concrete. $97 \%$ of households owned their houses. Around $30 \%$ of the surveyed households have a mobile phone.

We follow Haughton and Khandker (2009) in defining a poverty line to identify the poor from the non-poor. The line is determined based on the cost of basic needs where the cost of acquiring enough food for adequate nutrition is added as a measure of non-food essentials. ${ }^{9}$ Hence, we refer to the poverty incidence as the percentage of those households who fall below the basic needs consumption level. Overall, $81 \%$ of the reported income accrues to the non-poor, though almost $34 \%$ of the expenditures are consumed by poor households. 
Problems faced by households in the aftermath of the cyclone include the unavailability of transportation, price rises of essentials, unavailability of drinking water, food, fuel, and other supplies, and power supply disruptions (see Figure 3). Most households reported damages to kitchenware, plumbing, house structure, electrical wiring, etc. Kitchenware and plumbing were the most damaged items reported since households in the outer-islands typically have outdoor kitchens, and outdoor plumbing from roof gutters to water storage tanks. Flooding of the road outside and power supply cut-offs were the main reasons for losing work. On average, families went without electricity for two days. On average, households reported losing about two working days and seven school days for children.

More households view climate-related disasters as the most significant threat to their livelihoods. Figure 4 shows various stressors that households identify. The highest ranked stressors are natural hazards, i.e. cyclones, droughts and floods. Most pertinent here is that almost all households view cyclones as a major threat (97\%). After climate related hazards, monetary concerns are the next stressor; while overcrowding is the least significant stressor in the outer-islands.

\subsection{Loss and Damage}

As previously noted, the damage is the approximate replacement value of household assets damaged/destroyed by the cyclone. In order to properly estimate the damages to dwellings using replacement cost, we consulted with construction experts and distributors of building materials, furniture, and equipment. ${ }^{10}$ There is no insurance available in Tuvalu, hence all costs were always borne directly by the owners of assets; though they may have received external assistance (from the government or from external donors). Since we rely on a household survey, our estimates do not account for any damages to public buildings and public infrastructure. For the damages, we computed the estimated cost needed to rebuild or repair the damages to property and assets. ${ }^{11} 12$

People in the outer-islands live on fish, staple crops (e.g. taro and pulaka), fruit trees (e.g. breadfruit and coconut), vegetables (e.g. cucumbers and tomatoes) and livestock (pigs). ${ }^{13}$ Livelihoods in Tuvalu's outer islands heavily depend on these essentials. Losses in terms of livestock and agricultural plantations were substantial, and are included in our estimates. On the other hand, 'damage' refers to assets e.g. houses, local kitchens, outdoor toilets, water tanks, and others that were damaged and can be repaired. Overall, $95 \%$ of households reported that they incurred loss and damage.

Based on our summations from the survey responses, the estimated loss and damage to households in Tuvalu is AUD 1,796,497, which is almost 4.4\% of 2015 GDP. ${ }^{14}$ However, the overall loss and damage at the national level is estimated to be around $10 \%$ of the GDP. ${ }^{15}$ From the survey, we find that agriculture accounts for $5.3 \%$ of loss and damage while $14 \%$ and $4.2 \%$ goes to crops and livestock, respectively. Poor households bore the brunt of the cyclone incurring about half of the total loss and damages. 
Two islands, Nukufetau and the capital Funafuti, have lagoons and islets on their Western side, the side from which the storm surge came. They were thus largely shielded from the cyclone and experienced minimal direct impacts. A similar storm surge coming from the East would have been significantly more damaging as about half the population of the country, and the majority of infrastructure is located on Funafuti.

Only one island, Nukufetau, is surrounded and shielded by its islets and lagoon from all sides and is consequently much less exposed to storm surges. ${ }^{16}$ Vaitupu Island was affected, but not to the extent of the other five islands for whom the damage and loss information is provided below in Figures 5 and 6.

Nui and Nukulaelae islands were the most affected in terms of losses to crops and livestock (see Figure 5). Nui Island suffered particularly, with damage to housing, kitchens, outdoor toilets, water tanks, livestock, crop farms, vegetable gardens, fruit trees, and boats higher than in all other islands. The combination of low elevations and the narrowness of the island contribute to the high level of impact incurred there (see maps in Appendix A).

As determined by our calculations of the poverty threshold, and on average, the median loss and damage per household is very similar for poor and non-poor households. Given the different levels of income, however, both the median and spread of the relative loss and damage (to income) is much higher for poor households (Figure 7).

\subsection{Hazard}

TC Pam lasted for five days with wind velocities of more than $100 \mathrm{~km} / \mathrm{hr}$. Most research projects measure cyclone hazard using wind-speed indicators (e.g., Schumacher \& Strobl, 2011; Strobl, 2012), but Yonson et al. (2016) show that in some cases wind is not a good proxy for the storm hazard as it is experienced by households; most mortality, morbidity, and damage is associated with water rather than wind during TC events. In the case of Pam and Tuvalu, it is not the wind but the storm surge that impacted households, given the significant distance of all the Tuvaluan islands from the storm's centre. We therefore use the nearest distance from the location of each household to the cyclone path as our hazard indicator. This captures the strength and magnitude of the storm surge as it reaches the vicinity of the impacted household. On average, the distance of the cyclone path from the households in our survey sample is about $1000 \mathrm{~km}$.

\subsection{Exposure}

Peoples exposure to storm surge and coastal flooding risk is determined by their location. Most of the affected households, indeed most households on atoll islands, reside in areas prone to storm surges and flash floods. Given the small size of all the islands, the whole population of Tuvalu resides no more than one kilometer away from the sea. In almost all the islands of Tuvalu, populated areas are on the western side - the direction from which 
the storm surge came. ${ }^{17}$ In general, that meant that in most islands (except for, importantly, the capital Funafuti), the population was very exposed.

The total population of Tuvalu grew steadily from 9,026 in 1991 to 10,782 in 2012 . The percentage of the population living on the capital island, Funafuti, was also increasing from $32.6 \%$ in 1991 to $57 \%$ in $2012 .{ }^{18}$ We produced GIS maps linked to the household surveys and measured exposure using household distance to the coastline and household elevation (lower elevation areas are more prone to flooding associated with storm surges).

Figure 8 provides some statistics about the households' exposure. Households that live in houses that are less than 5 meters above the low water line are described in panel (a), while households whose residence is less than 100 meters from the coast are described in panel (b). We further distinguished between the poor and non-poor households using the definition of poverty described earlier. It is obvious to observe that the residents of Nui and Nukulaelae are the most exposed, with some additional significant exposure in Nanumea.

Many of our surveyed households reported surges from TC Pam entering their homes. On Nui, 98\% of households reported that surges from the TC Pam entered their homes. Similarly, Nanumaga, Nanumea, Niutao, and Nukulaelae reported 15\%,60\%, 32\% and 66\%, respectively - again, this clearly corresponds with the exposure data described in figure 8 that identified Nanumea, Nui, and Nukulaelae as the most exposed.

\subsection{Vulnerability}

Household characteristics such as income, household size and the structural strength of the house they reside in were used as indicators representing the vulnerability of households. Household income distribution in Tuvalu's outer-islands shows substantial income inequalities with $20 \%$ of the households earning less than AUD50 per month. Around $50 \%$ of the population earns below AUD150 per month, whereas the top $10 \%$ earn more than AUD475 per month. The annual per capita income is USD414. ${ }^{19}$ This poverty in the outerislands also corresponds with almost $40 \%$ of the population living in non-concrete houses.

Although people in the outer-islands are less dependent on cash because they have access to natural resources to support their daily food consumption, money is increasingly being used in purchasing imported basic food items as substitutes for subsistence consumption. Practically, people in the outer-islands often receive remittances from their families working in Funafuti and overseas to pay for basic food items, electricity, and community and church contributions. The government also indirectly subsidizes electricity and shipping charges for the outer-islands by charging for these services below costs. In return, families, communities and churches serve as safety nets in times of hardship. These support instruments are one a reason there are hardly any families displaying abject poverty. However, the government, customs, and traditions play vital roles in ensuring the good well-being of the people. 


\subsection{Responsiveness}

The importance of early warning as a priority for disaster risk reduction is well recognized (e.g., Hallegatte, 2013). In anticipation of the cyclone, 51\% of households moved to safe shelters, and $42 \%$ shielded or covered windows. As expected, food and water were the most stocked-up items just before the cyclone. Surprisingly, strengthening the building they live in was only undertaken by a minority of the respondents (Figure 9). This failure to undertake significant strengthening can be explained by the timing of the early warning that was provided. Very few households received warning 48 hours ahead of the cyclone - a lag that would have enabled more preparation and strengthening. Still warning was sufficient so that $45 \%$ of households shifted their assets and valuables in anticipation of the cyclone (24\% shifted their assets to other houses and $21 \%$ elevated them within their own houses).

The majority of people received cyclone warnings from the radio broadcast and island community alarms, but 39\% did not receive any warnings of the cyclone. Fifteen percent of households were not aware of any safe shelters that were available for them during the cyclone. The average time a household had to travel to reach a safe shelter is 13 minutes, but $57 \%$ of households never did shift to these shelters. Around $26 \%$ received some cyclone response training.

\subsection{Poverty}

Incomes of these poor households are far less than what is needed to cover losses incurred. Only $10 \%$ of households have reported saving some money in the National Bank of Tuvalu (NBT). ${ }^{20}$ The average amount saved is about $2 \%$ of monthly income. On average, non-poor incur more actual damages (in dollar value) than the poor by a small margin. However, poor households suffer six times more than non-poor households in terms of loss and damages, relative to income. If households were to use all their income to rebuild back the damages, it would take up to at least 15 months for a non-poor household to rebuild the damages and recover back to normal, while a poor household takes at least 93 months.

\section{Estimation Results}

Table 3 presents the estimation results of our econometric model explaining the log of loss and damage per household (the measures collected from the survey, as described in section 4). The benchmark regressions (equation 1) are estimated for the full survey sample (305 households) and separately for poor and non-poor households as previously defined (columns 1-3). F-tests indicate overall statistical significance of the model, and the $\mathrm{R}^{2}$ values indicate the overall goodness of fit of the model (0.28-0.33) suggesting about a third of the variability of the household damage and loss is correlated with the vulnerability, exposure, and responsiveness indicators we measured for each household.

For the vulnerability indicators, we find that income per capita is negatively associated with loss and damage in poor households (column 2) - i.e., the lower the income, the higher the 
losses. In richer households the association is positive (richer households have more assets of higher value that can be damaged and more crops and land because of which they can experience higher income loss). It is only for the poor households that the association is statistically significant (as the coefficient is much larger). For these poorer households, additional income is probably translated into improved ability to mitigate damages, resulting in this negative association. This $U$ shaped association between loss and damage (on the $y$-axis) and income (on the x-axis) has not been reported in the literature before, as far as we are aware. There is no clear association between household size and the dependent variable (loss and damage). Unsurprisingly, those households that have a cement house experience lower damages; though this association is statistically not very robust.

In terms of exposure, the closer the households are to the coast, and the lower their elevation, the higher the damage and loss these households experience, holding everything else constant. The total disatance measuring the width of the island at the household's location (another proxy of possible exposure) is also statistically signficant and positive (for the overall sample; though the coefficients estimated in the sub-samples are of similar magnitude). The size of this coefficient, the impact of total distance is an order of magnitude lower than the one meausuring the disatance to the nearest coast. As such, these are all not surprising findings, but are very important as projected sea-level rise that is associated with climate change will make houses in Tuvalu inevitably much more exposed to these distant cyclones as the islands are reduced in size and the elevation above sea level is reduced. We investigate this issue further in the next section.

We also observe that the closer the households were to the cyclone's path, the higher the stated losses and damages were. Interestingly, the 'decay' in the level of damage as the distance from the cyclone increases is not very large. For every additional kilometer of distance the decrease in loss and damage because of cyclone Pam is $0.5 \%$. This is an important point. It suggests that our assessment of risk for Atoll Islands should take into account also the very distant cyclones (such as Pam) that are currently not assessed as potentially destructive in most risk models-e.g., in the PCRAFI Risk Assessment Model. A cyclone that passes $1000 \mathrm{~km}$ away from a location, as was the case for Pam for Tuvalu, is not typically modelled as causing any damage. ${ }^{21}$

In terms of the ability to respond to an oncoming cyclone, we find that households that received early warning (at least 12 hours in advance) did indeed manage to reduce their damage and loss. ${ }^{22}$ Interestingly, the efficacy of early warning was higher for poor households in reducing loss and damage; though the differences between the two subsamples are not statistically significant. Cyclone response training and ex ante house strengthening both appear to reduce loss and damage but these impacts are largely driven by their efficacy for richer households. One can speculate why that might be the casemaybe this is related to the elevated ablity of non-poor households to affectively act upon the information they receive-but we have no direct evidence to demonstrate that this indeed might be the reason for these observed differences. 
We investigate the efficacy of several additional control variables in Table 3, columns (4) to (7). The only variable for which we find a consistent, statisically signficant finding, is the binary indicator measuring whether a household shifted assets to a safe place. Other variables were not statisically associated with the loss and damage in any materially consistent way.

\section{Hypothetical Scenarios of DRR Policies}

The results from Table 3 allow us to identify the empirically observed relationship between vulnerability, exposure, and hazard intensity and the actual loss and damage from a distant cyclone, as experienced by households living on low-lying atoll islands. These results also allow us to construct hypothetical scenarios in which vulnerability and exposure are changed (via policy choices) and estimate the likely consequence these changes may have on cyclone loss and damage. These estimates are presented in Tables 4-5.

Table 4 presents the observed loss and damage totals, as calculated from the survey responses. The first column represents the totals obtained directly from the survey responses. The second column calculates what would have been the total loss and damage experienced by the whole population of the outer islands, as the survey only reached a sample of the households living on these islands. The third column in the top panel calculates what would have been the damage and losses had the storm affected the whole population of Tuvalu, including the capital Funafuti (where about half the population of the country resides).

These calculations indicate that the total household damage and loss in Tuvalu-as a consequence of cyclone Pam-was about AUD 1.9 million. ${ }^{23}$ Of that amount, about a half (AUD 0.9 million) was lost to poor households - see the second row in Table 4. Had the cyclone hit Funafuti as well (which would have been the case if the wave surges had come from the East rather than the West), the total loss and damage would have been an estimated AUD 6 million (14\% of GDP).

The estimates we obtained in the previous section enable us to predict loss and damages that correspond with the minimum, mean and maximum scenarios for selected explanatory variables. Equation 1 was employed to estimate these predicted values using the estimated coefficients from Table 3 and the actual observed values of all variables except for the hypothetical scenario being examined. As we already observed, there are variations in cyclone impacts across households and islands and this allows us to contemplate the likely impacts had these households exposure and vulnerability been different. Although these hypothetical scenarios are not entirely credible and present extreme-case scenarios, we purposely seek to understand the differential impacts imposed by various levels of vulnerability, exposure and hazard for the islands of Tuvalu.

Table 5 presents the total predicted values of these hypothetical scenarios across households. In scenarios 1-3, we examine only households classified as poor, while 
scenarios 4-23 examine the whole affected population of the outer islands (while still maintaining the assumption that Funafuti is unaffected).

In Scenario 1, we set the income per capita to its lowest recorded value across households. Similarly, we assigned observed values of the mean income per capita and maximum income per capita for Scenario 2 and Scenario 3, respectively. As expected, the higher income per capita is associated with lower loss and damages. Note that for these scenarios we used the sample of poor households. Likewise, Scenarios 6-14 show adjusted exposure using the distance to the coast and elevation with different cases, assigning different observed values of minimum, mean and maximum across all households. Scenarios 15-17 change the parameters of the hazard, while scenarios 18-23 investigate what happens when different preparation for the cyclone is instituted.

For poor households, we observe that had all of them had the income of the lowest per capita income, the damage associated with the cyclone would have been almost $40 \%$ higher (scenario 1). In contrast, had they all had the highest income in the full sample, the damages would have been $80 \%$ lower (scenario 3). For the full sample, had all houses been constructed of cement (instead of wood), the damage would have been only about $8 \%$ lower - though it is important to note that most houses are already made of cement.

The extreme exposure of Tuvaluan households is demonstrated starkly when we examine scenarios 6-14. If all Tuvaluan households were living at minimum distance the coast (rather than a few additional dozen meters inland), the damage wrought by a Pam-like cyclone would have been $50 \%$ higher (scenario 6). Equally, if all were living at the minimum elevation, damage would have been almost twice as high (scenario 9). As, ultimately, both of these things will happen as a result of predicted sea-level rise, it is easy to see how significant is future cyclone risk for atoll islands.

The distance to the cyclone path is also of specific concern. In this case, we note that a cyclone that was a little bit closer (and still $900 \mathrm{~km}$ away) would have increased the damage and loss associated with the cyclone by $26 \%$ (scenario 15 ). In terms of the possibilities of generating better preparation and response to the cyclone, the data is suggestive of some potentially beneficial interventions. In particular, strengthening all houses before the cyclone would have reduced the damage by $8 \%$, while having everyone (a representative from each household) attend a cyclone response training would have reduced damage by $17 \%$ - scenarios 19 and 21, respectively. Most striking is the apparent efficacy of supplying a better early warning system (scenario 22-23). In this case, if all were to receive an effective early warning notice (at least 12 hours before the cyclone surge), the impacts would have been lower by $77 \%$. This finding, while a specific quantitative result of benefit, is in line with other research that identifies early warning system as by far the best cost effective way of reducing disaster (and specifically cyclone) mortality. 


\section{Conclusions and Policy}

The study of cyclone risk for small low-lying islands is important as the intensity of cyclones in the Pacific is predicted to increase and sea levels are predicted to rise. In many ways, a small island developing state like Tuvalu can serve as the 'canary in the mine' pointing to the emerging risks that are being generated as we increasingly experience the impacts of climatic change. In Tuvalu, 70 percent of households live less than 200 meters from the coastline and with an elevation of no more than 5 meters above sea-level. Households are thus acutely vulnerable to storm surges caused by cyclones even if the cyclone itself passes very far away. In order to investigate the impacts of cyclones on low-lying atoll islands, we conducted a survey in Tuvalu after the islands incurred severe damage from storm surges generated by Tropical Cyclone Pam (March, 2015).

We first observed that poor households suffered far more losses and damages relative to their income than the non-poor. This inequity has previously been reported in urban areas in developing countries as poor households are more likely to live in floodplains or on steep hillsides. Yet, it is less expected on a Pacific Island where locational decisions of households are mostly dictated by generations-old land tenure rather than through market mechanisms that force low-income households to locate in riskier areas. Having summarized the aggregate impact of the cyclone storm surge on households, we then examined the role of the hazard, exposure to it, and vulnerability to cyclones in shaping these losses.

Lastly, we constructed hypothetical scenarios in which the exposure and vulnerability of households is assumed to change, and calculated the estimated loss and damage they would have experienced. We find large variations in loss and damage that is associated with both exposure and vulnerability, and quantify these changes against the various scenarios we assessed. These hypothetical calculations can now serve as the main input into careful assessments of the feasibility and desirability of distinct disaster risk reduction (DRR) policies. Importantly, the need for careful assessment of DRR policies was central in the discussions leading up to the international Sendai Agreement that was signed by almost 200 countries at the same time that cyclone Pam was hitting Tuvalu.

Apart from the household exposure to cyclones, many other assets, activities and services were adversely affected by the cyclone, too. Offices and commercial structures, medical clinics, transportation and communication infrastructure, retail shops, educational institutions, public utilities and social amenities were all damaged by Pam. Furthermore, there were disruptions to services and amenities; households reported problems like disruption of power, water, transportation, fuel and other supplies, and working and school days that were lost. These problems are associated with indirect losses which are difficult to measure in monetary terms and were not accounted for here.

Similarly, TC Pam may have adversely affected the health of residents in the outer islands. These are also difficult to quantify. It is likely that the overall damage and loss, as experienced not only by households but also include the impact on the government, is more 
than twice as large as what was experienced by households (which is what we measured in this paper).

It is important to remember that the most heavily populated island, and the one that includes much of the infrastructure including the international deep-sea port, the airport, and most government facilities, was not damaged at all. Had the storm blew from the East, rather than the West, the impact on Funafuti could have been very different. If Funafuti was as exposed to this cyclone as the outer islands, the damage and loss associated with the cyclone would have been about three times higher, even though Funafuti only contains about half of the population of the country.

Households in Tuvalu have no insurance available for them, nor any other way of transferring risk. As such, the only policy levers that are available for them is to mitigate damages through changing their exposure and vulnerability. In the absence of insurance and formal social safety nets, the cost of repairs and replacements have to be borne by families regardless of their income, and that places an immense burden on poor households. Under these circumstances, it is not surprising that the government of Tuvalu has been contemplating providing assistance to impacted households by paying for some of the rebuilding costs associated with the impact of TC Pam. This places a significant burden on a government that has a very limited ability to collect additional tax revenue or borrow. Thus, questions about the desirability of government assistance post Pam also are connected to other questions about the government's fiscal position and the sustainability of its spending. In this context, it seems advisable for policy makers to consider alternative options to provide ex-post assistance to affected households and at the same time protect the government's fiscal stance. One possibility would be to explore ways to establish implicit or explicit saving accounts (sovereign funds), contingent credit lines or insurance contracts that can provide this buffer for disaster recovery needs and paid for through the Warsaw Internatinonal Mechanism for Loss and Damage (Mechler and Schinko, 2016). 
Figure 1: Tuvalu Islands and the Trajectory of the TC Pam.

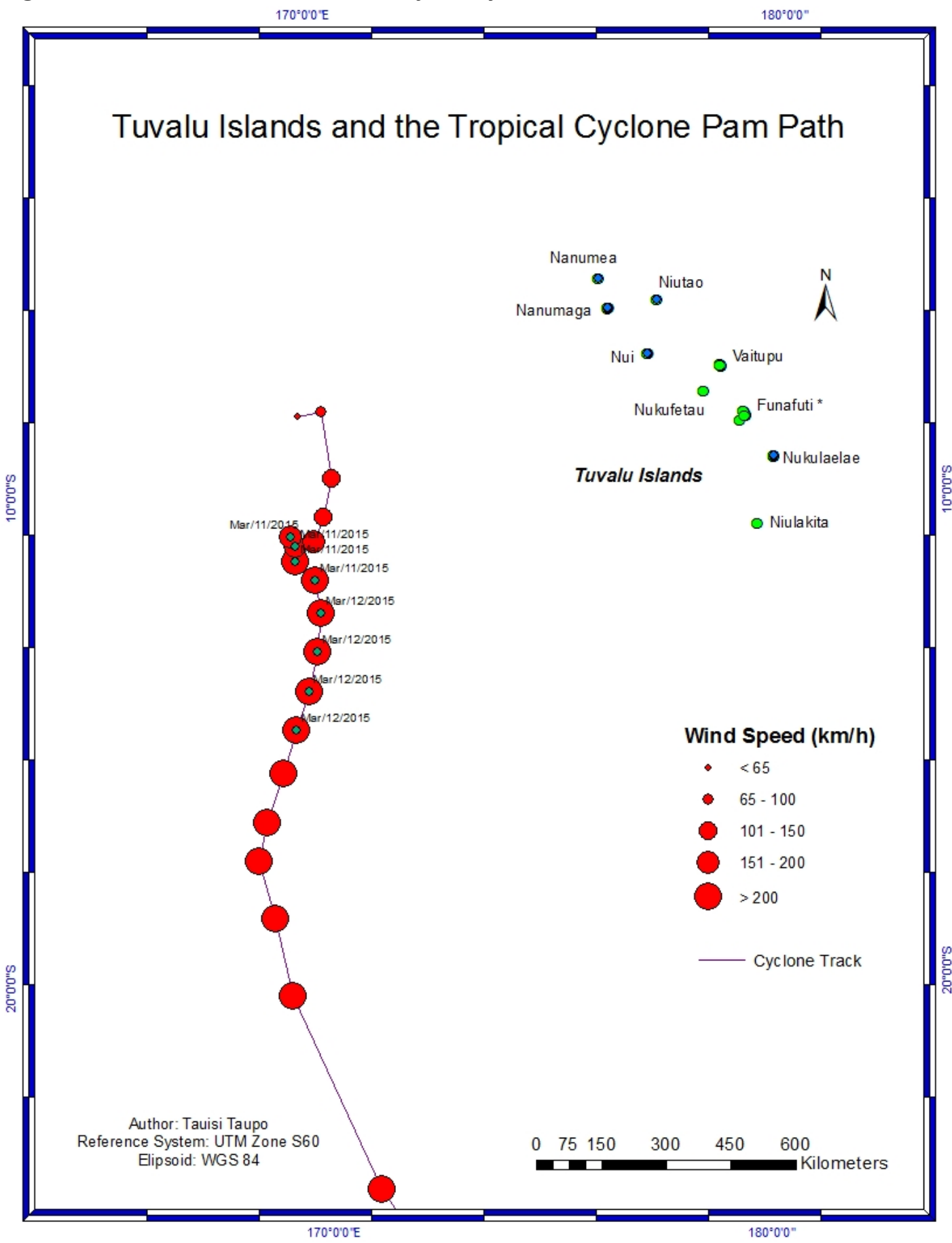

Note: The green dots on the TC Pam track denote the points when the Islands of Tuvalu were hit the hardest by the cyclone. The tracking dots are measured at 6 hour intervals. The blue dots represent the affected islands that were included in our Survey. 
Figure 2: Asset ownership.

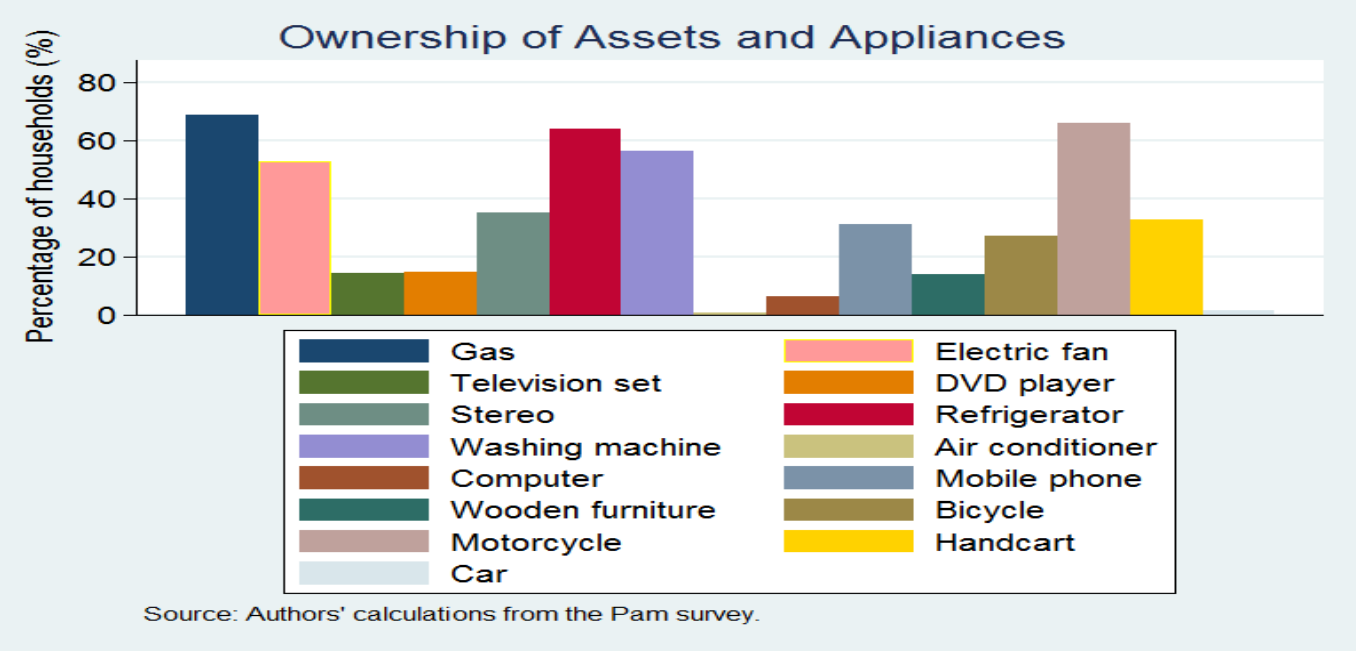

Figure 3: Cyclone impacts.

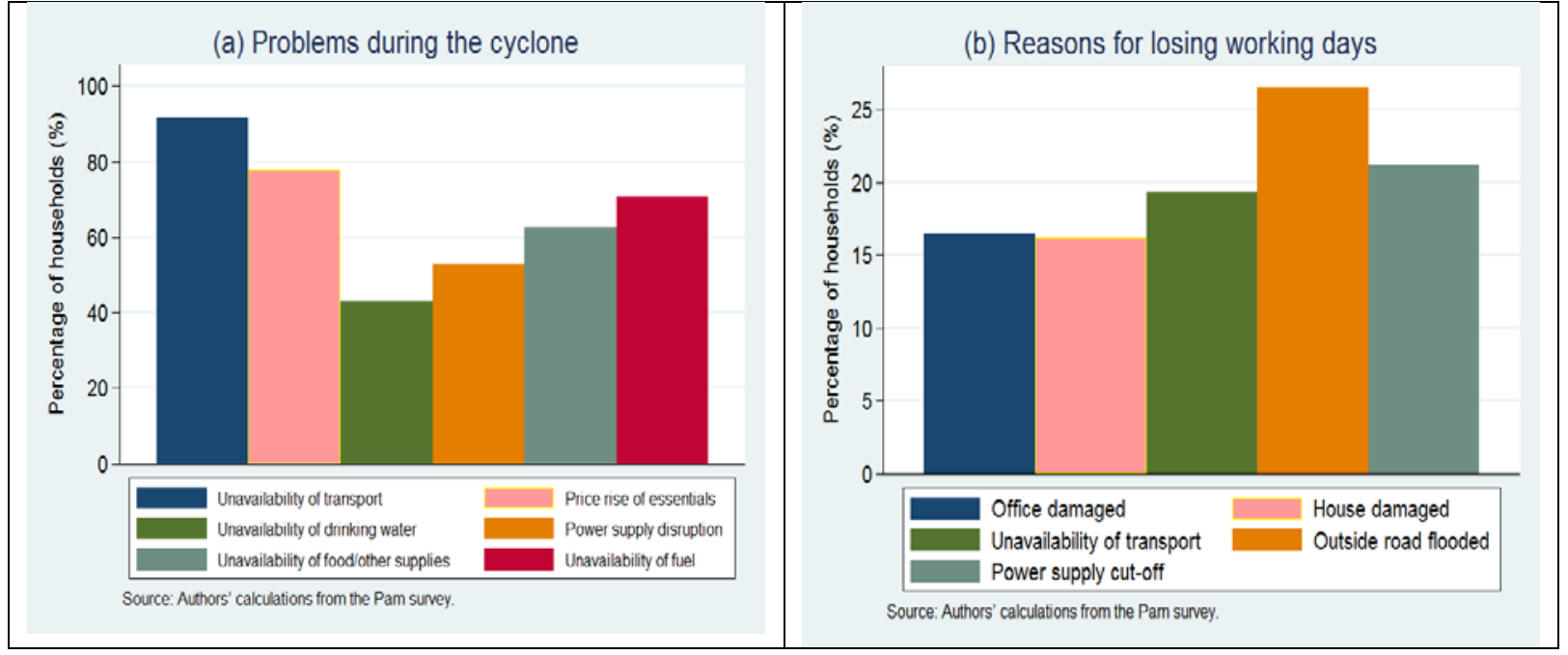

Figure 4: Multiple stressors affecting households.

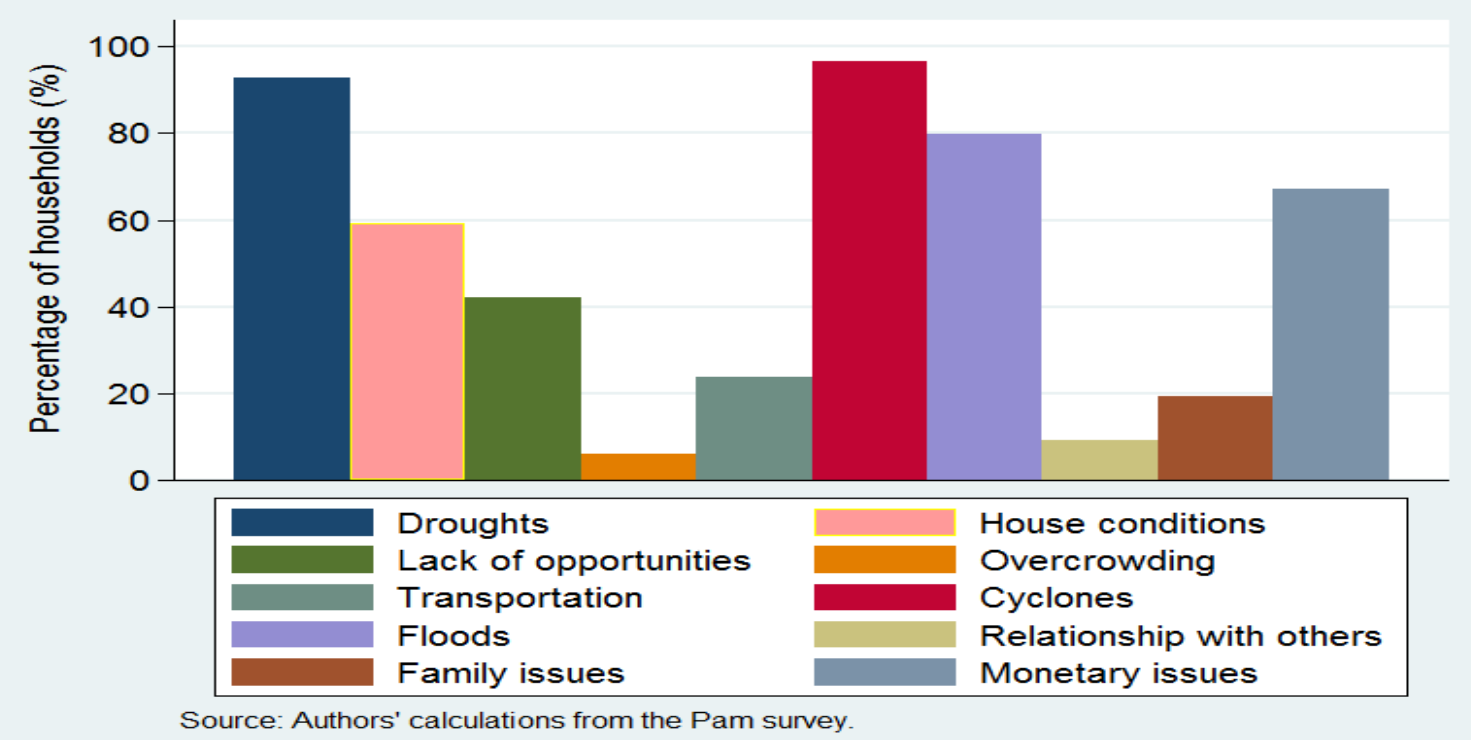


Figure 5: Losses incurred by households.

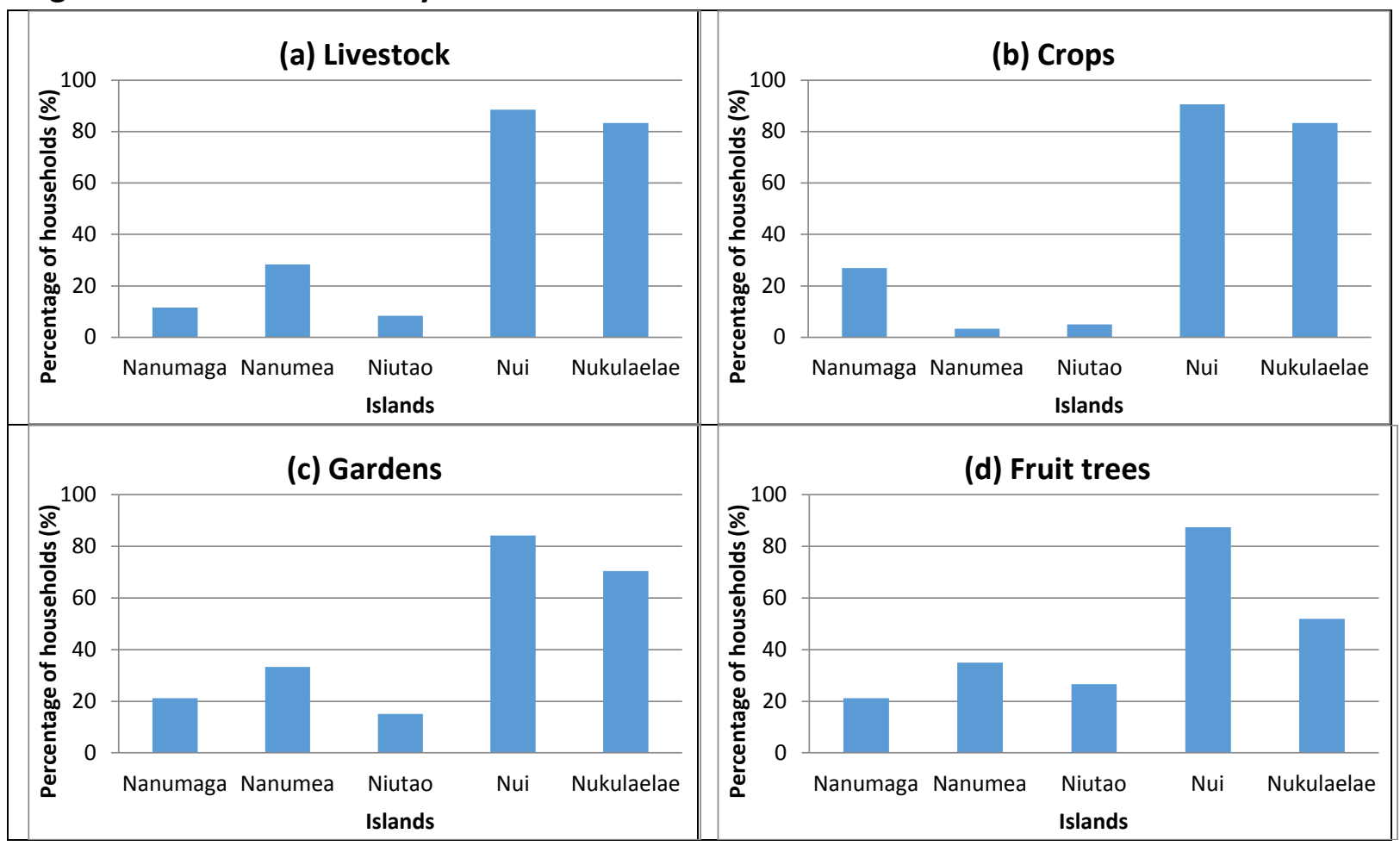

Source: Authors' calculations from the Pam survey.

Figure 6: Damages incurred by households.

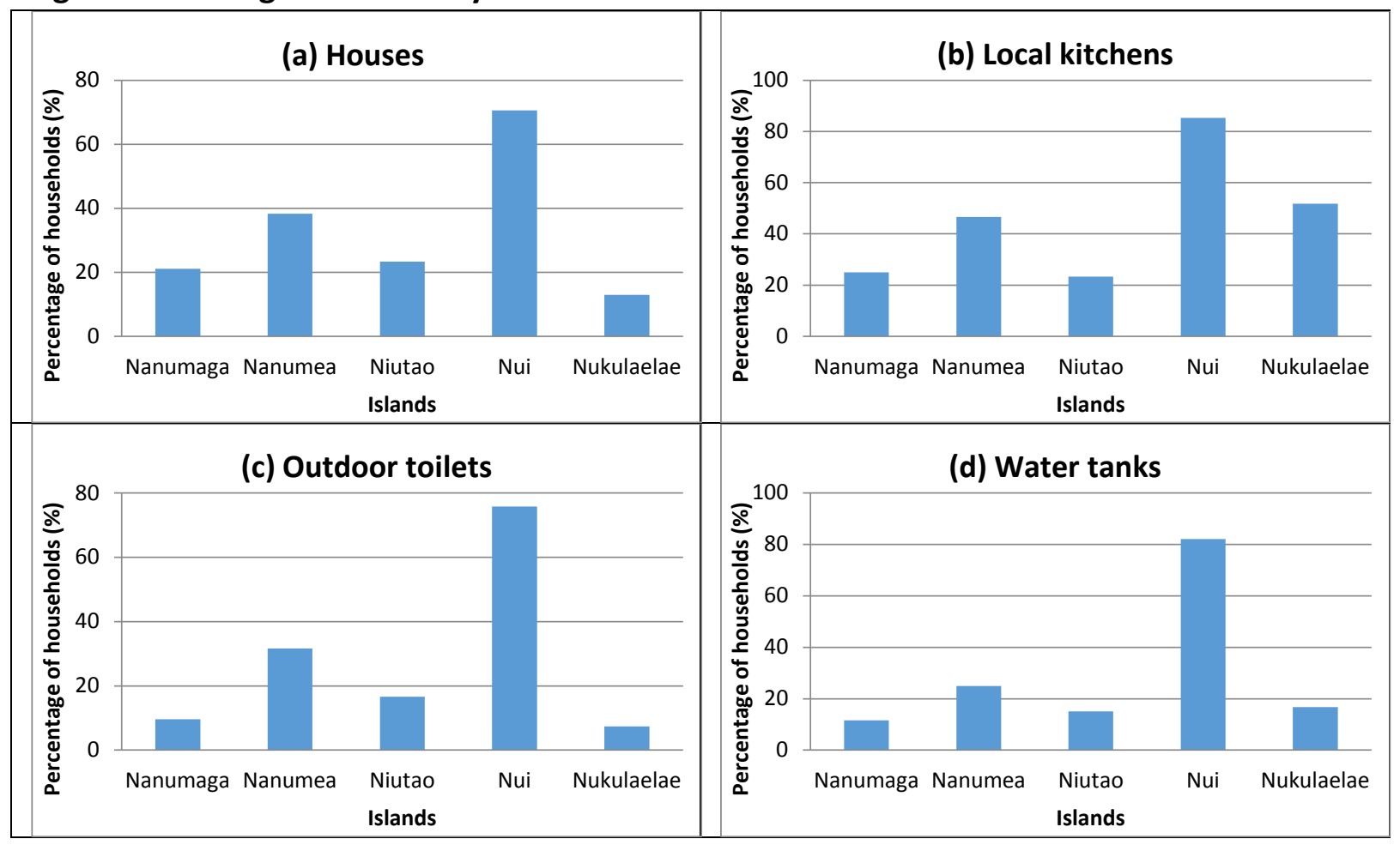




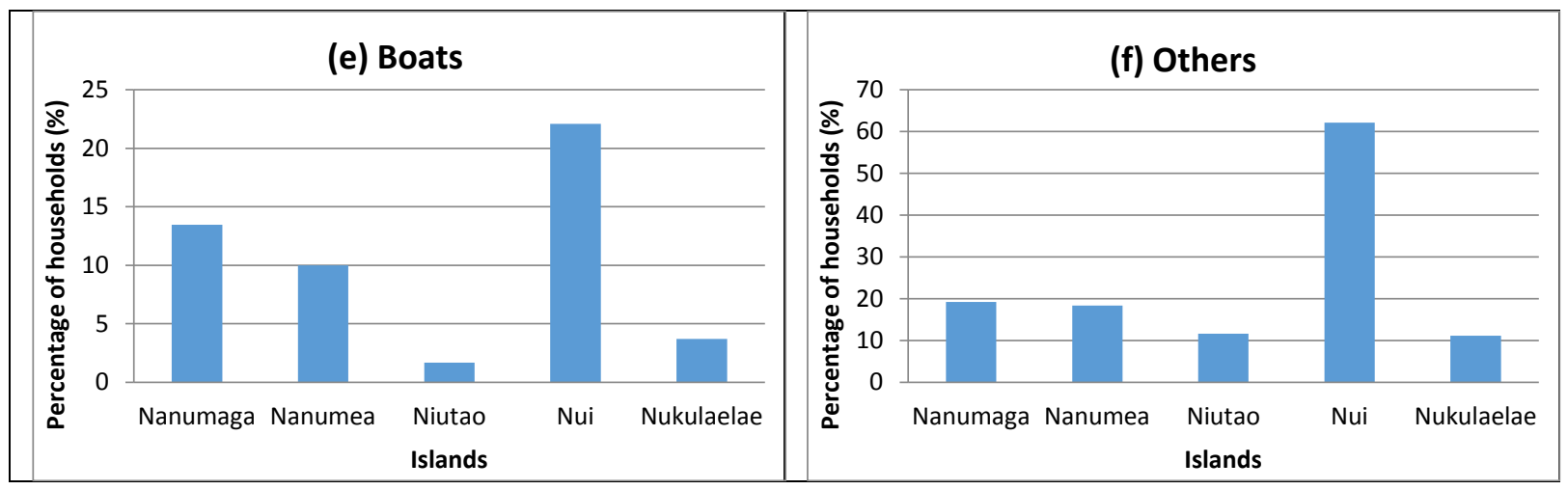

Source: Authors' calculations from the Pam survey.

Figure 7: Income, Expenditure, Loss and Damage by income classification.

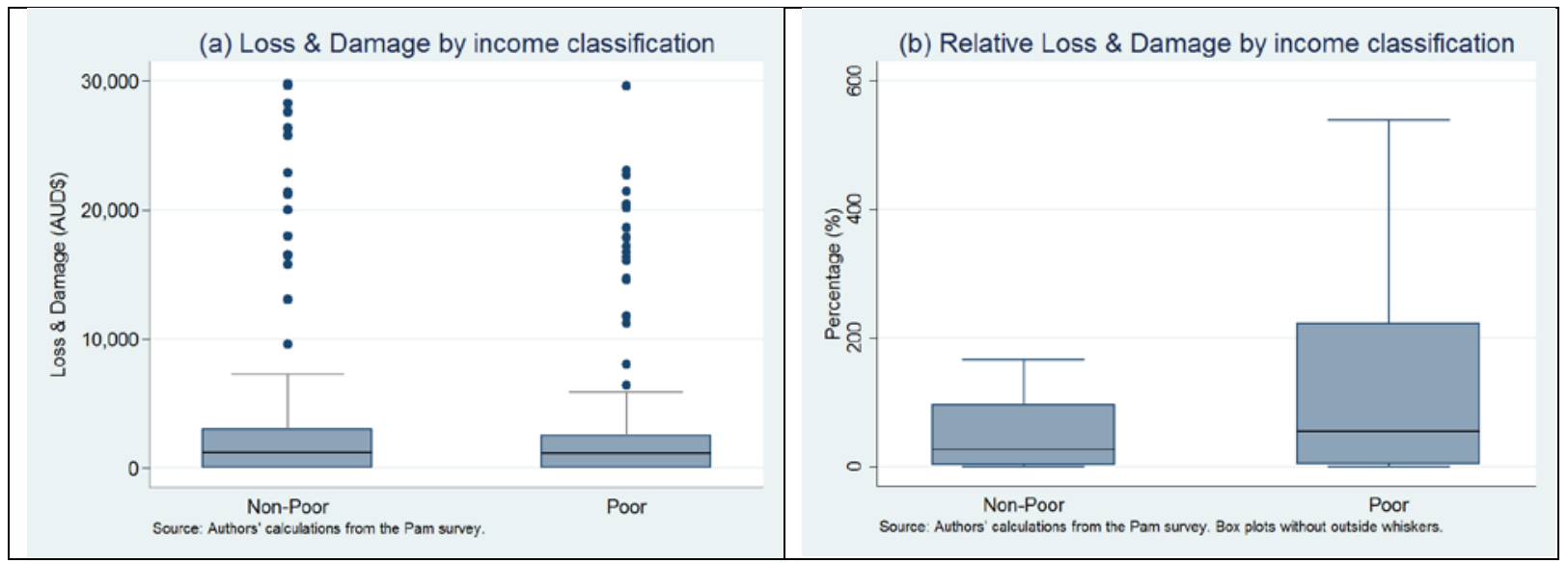

Figure 8: Household exposure

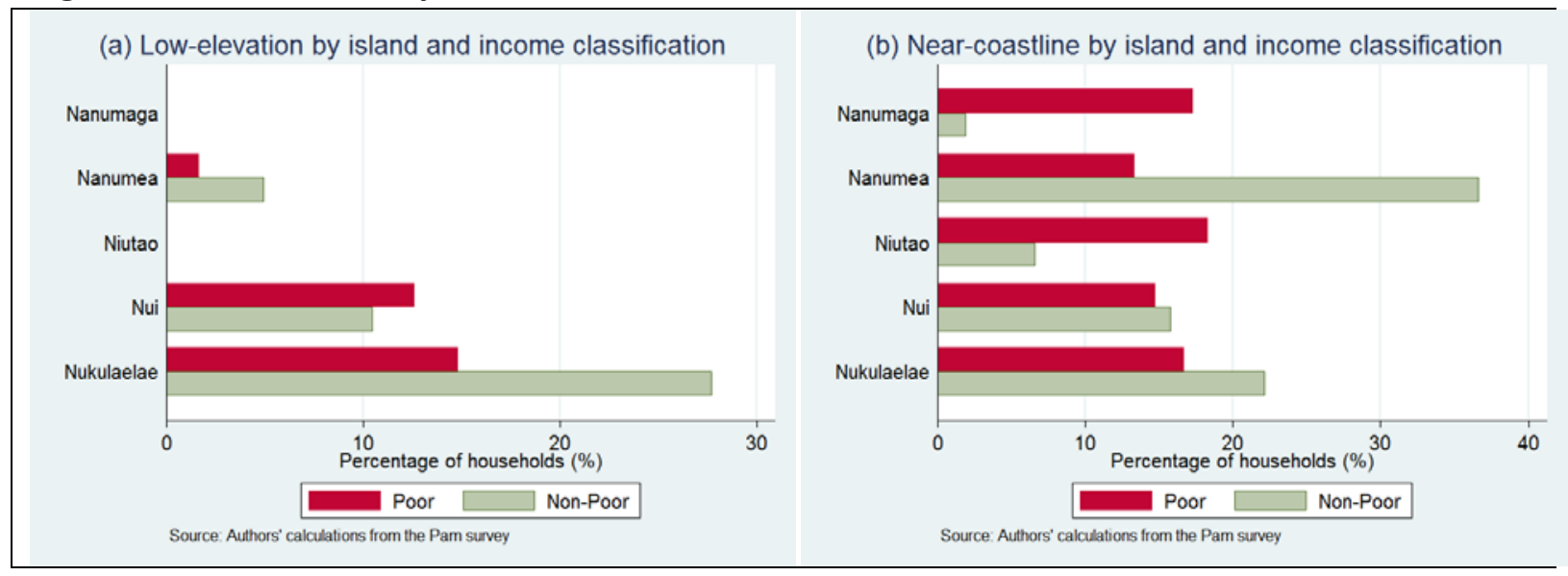


Figure 9: Responding to the cyclone.

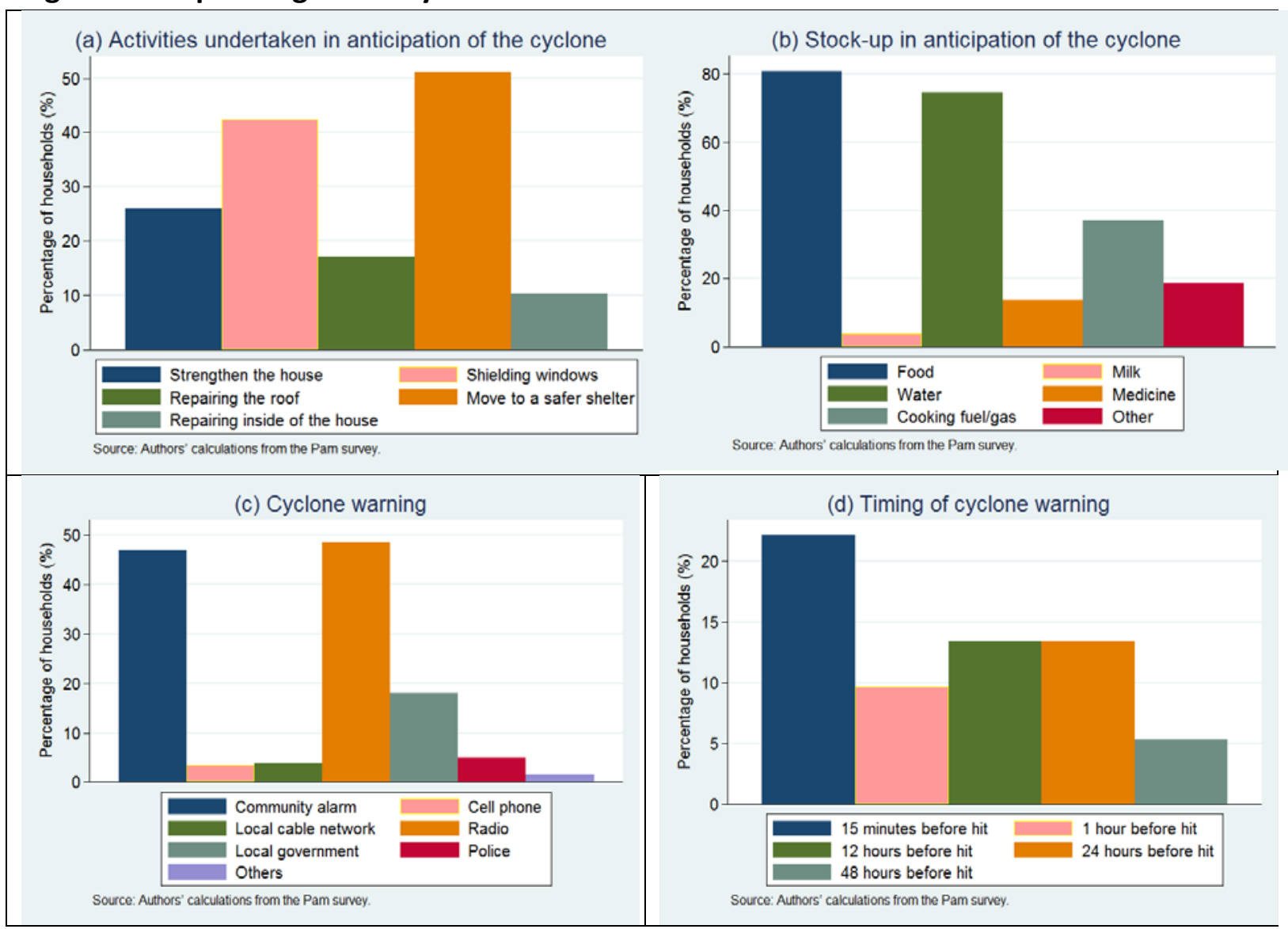


Table 1: Description of variables and their sources

\begin{tabular}{lcccc}
\hline Variable & Mean & STD & Min & Max \\
\hline The logarithm of loss and damage (in AUD) & 6.49 & 2.11 & 3.69 & 10.30 \\
The logarithm of income per person (in AUD) & 3.63 & 1.00 & 0.69 & 7.54 \\
Loss and damage (in AUD) & 3,406 & 6,304 & 40 & 29,800 \\
Monthly income per person (in AUD) & 65.54 & 142.48 & 0 & 1,875 \\
Number of persons in the household & 4.8 & 2.6 & 1 & 15 \\
Strong house structure, 1 if cement & 0.83 & & 0 & 1 \\
Distant to the nearest coastline in meters & 166 & 107 & 27 & 563 \\
Elevation of household in meters & 9.4 & 3.5 & 1.8 & 17.7 \\
Total distant to the coasts (land width) in meters & 889.1 & 485.1 & 113.9 & 2425.2 \\
Distant from household to the cyclone path in km & 973.53 & 68.50 & 906.13 & 1100.09 \\
House preparation for cyclone, 1 if house was & 0.51 & & 0 & 1 \\
strengthened & & & & 0 \\
Training/capacity-building experience from cyclone & 0.74 & & & 1 \\
response workshops, 1 if yes & & & & \\
Received cyclone warning at least 12 hrs in advance, 1 if & 0.32 & & & 1 \\
Yes & & & & \\
\hline Note: The only variable for which we do not have the full 321 responses is income (only 305 responses). All \\
variables were based on authors' calculations from the primary data collected in the survey. Geo-location \\
information is based on Global Positioning System (GPS) locations of households using reference system UTM \\
Zone S60 with ellipsoid WGS 84 and the Digital Elevation Model (DEM). & &
\end{tabular}

Table 2: Risk, Vulnerability and Resilience indicators

\begin{tabular}{|c|c|c|c|}
\hline & Indicators & Poor & Non-poor \\
\hline \multirow[t]{4}{*}{ Risk } & Loss (mean) & 680 & 942 \\
\hline & Damage (mean) & 2518 & 2680 \\
\hline & Loss and Damage (mean) & 3186 & 3612 \\
\hline & Loss and Damage over income (mean) & 93 & 15 \\
\hline \multirow[t]{6}{*}{ Vulnerability } & Monthly Income (mean) & 97 & 436 \\
\hline & Households (\%) & 51.09 & 48.91 \\
\hline & Number of persons in the household (mean) & 5 & 4 \\
\hline & Number of dependents i.e. children and elderly (mean) & 3 & 3 \\
\hline & Household lived in concrete and wood house (\%) & 85 & 81 \\
\hline & Distance from the cyclone shelter in minutes (mean) & 14 & 12 \\
\hline \multirow[t]{2}{*}{ Exposure } & Households live within 100 meters from the coast (\%) & 31 & 34 \\
\hline & Residing in low elevation (\%) & 13 & 18 \\
\hline Hazard & Distant from the cyclone path in kilometers (mean) & 973.49 & 973.57 \\
\hline \multirow[t]{9}{*}{ Respond Ability } & Strengthen house in preparation for the cyclone (\%) & 55 & 45 \\
\hline & Shift valuable assets to safe place (\%) & 47 & 43 \\
\hline & Households attended cyclone respond workshops (\%) & 74 & 75 \\
\hline & Households received a cyclone warning (\%) & 63 & 60 \\
\hline & Percentage of income usually saved (\%) & 2.85 & 2.90 \\
\hline & Household evacuated to the cyclone shelter (\%) & 44.5 & 41.1 \\
\hline & Social safety net (\%) & 29.9 & 22.9 \\
\hline & Access to credit $(\%)$ & 32.9 & 33.1 \\
\hline & Households received some form of assistance (\%) & 94.5 & 100.0 \\
\hline Relocation & Prefer to relocate to a safer place (\%). & 44 & 37 \\
\hline
\end{tabular}

Source: Authors' calculations from the Pam survey. 
Table 3: Model estimation results explaining the log of damages

\begin{tabular}{|c|c|c|c|c|c|c|c|}
\hline & $\begin{array}{l}\text { All } \\
(1) \\
\end{array}$ & $\begin{array}{l}\text { Poor } \\
\text { (2) }\end{array}$ & $\begin{array}{c}\text { Non-Poor } \\
\text { (3) }\end{array}$ & $\begin{array}{l}\text { All } \\
(4)\end{array}$ & $\begin{array}{l}\text { All } \\
(5) \\
\end{array}$ & $\begin{array}{l}\text { All } \\
(6) \\
\end{array}$ & $\begin{array}{l}\text { All } \\
(7) \\
\end{array}$ \\
\hline \multicolumn{8}{|c|}{ Vulnerability } \\
\hline \multirow[t]{2}{*}{ lincrcap } & -0.0467 & $-0.537^{* *}$ & 0.212 & -0.0180 & -0.0554 & -0.0654 & -0.0348 \\
\hline & $(0.113)$ & $(0.271)$ & $(0.223)$ & (0.110) & $(0.112)$ & $(0.115)$ & $(0.112)$ \\
\hline \multirow[t]{2}{*}{ hholdsize } & 0.0680 & 0.0521 & 0.0702 & 0.0475 & 0.0595 & 0.0683 & 0.0479 \\
\hline & $(0.0445)$ & $(0.0644)$ & $(0.0628)$ & $(0.0433)$ & $(0.0441)$ & $(0.0445)$ & $(0.0434)$ \\
\hline \multirow[t]{2}{*}{ strhouse } & $-0.514^{*}$ & -0.519 & -0.440 & -0.226 & -0.470 & $-0.524^{*}$ & -0.242 \\
\hline & $(0.290)$ & $(0.436)$ & $(0.391)$ & $(0.288)$ & $(0.287)$ & $(0.290)$ & $(0.290)$ \\
\hline \multicolumn{8}{|l|}{ Exposure } \\
\hline coastdist & $\begin{array}{c}-0.00565^{* * *} \\
(0.00103)\end{array}$ & $\begin{array}{c}-0.00349^{* *} \\
(0.00150)\end{array}$ & $\begin{array}{c}-0.00800^{* * *} \\
(0.00147)\end{array}$ & $\begin{array}{c}-0.00479^{* * *} \\
(0.00102)\end{array}$ & $\begin{array}{c}-0.00549^{* * *} \\
(0.00103)\end{array}$ & $\begin{array}{c}-0.00568^{* * *} \\
(0.00104)\end{array}$ & $\begin{array}{c}-0.00484^{* * *} \\
(0.00102)\end{array}$ \\
\hline \multirow[t]{2}{*}{ elevat } & $-0.128^{* * *}$ & $-0.185^{* * *}$ & -0.0746 & $-0.146^{* * *}$ & $-0.133^{* * *}$ & $-0.124^{* * *}$ & $-0.143^{* * *}$ \\
\hline & $(0.0352)$ & $(0.0485)$ & $(0.0526)$ & $(0.0343)$ & $(0.0348)$ & $(0.0354)$ & $(0.0347)$ \\
\hline \multirow[t]{2}{*}{ totdist } & $0.000409^{* * *}$ & 0.000348 & $0.000417^{*}$ & $0.000422^{* * *}$ & $0.000369^{* * *}$ & $0.000408^{* * *}$ & $0.000417^{* * *}$ \\
\hline & $(0.000156)$ & (0.000219) & $(0.000228)$ & $(0.000151)$ & $(0.000155)$ & $(0.000156)$ & $(0.000153)$ \\
\hline \multicolumn{8}{|l|}{ Hazard } \\
\hline \multirow[t]{2}{*}{ cycpdist } & $-0.00506^{* * *}$ & -0.00286 & $-0.00540^{*}$ & $-0.00554^{* * * *}$ & $-0.00553^{* * *}$ & $-0.00495^{* * *}$ & $-0.00548^{* * *}$ \\
\hline & $(0.00190)$ & $(0.00268)$ & $(0.00282)$ & $(0.00184)$ & $(0.00188)$ & $(0.00190)$ & $(0.00185)$ \\
\hline \multicolumn{8}{|c|}{ Responsiveness } \\
\hline \multirow[t]{2}{*}{ strhou } & $-0.478^{* *}$ & -0.0535 & $-0.802^{* *}$ & $-0.415^{*}$ & -0.377 & $-0.498^{* *}$ & $-0.423^{*}$ \\
\hline & $(0.235)$ & $(0.366)$ & $(0.317)$ & $(0.228)$ & $(0.236)$ & $(0.236)$ & $(0.232)$ \\
\hline \multirow[t]{2}{*}{ capacity } & $-0.623^{* *}$ & -0.390 & $-0.691^{*}$ & $-0.630^{* *}$ & $-0.652^{* *}$ & $-0.646^{* *}$ & $-0.650^{* *}$ \\
\hline & $(0.269)$ & $(0.376)$ & $(0.404)$ & $(0.260)$ & $(0.266)$ & $(0.270)$ & $(0.262)$ \\
\hline \multirow[t]{2}{*}{ warn } & $-0.962^{* * *}$ & $-1.094^{* * *}$ & $-0.818^{* *}$ & $-0.913^{* * *}$ & $-0.916^{* * *}$ & $-0.941^{* * *}$ & $-0.894^{* * *}$ \\
\hline & $(0.254)$ & $(0.363)$ & $(0.381)$ & $(0.246)$ & $(0.251)$ & $(0.254)$ & $(0.247)$ \\
\hline \multicolumn{8}{|c|}{ Other Variables } \\
\hline \multirow[t]{2}{*}{ ashift } & & & & $0.994^{* * * *}$ & & & $0.948^{* * *}$ \\
\hline & & & & $(0.218)$ & & & $(0.272)$ \\
\hline \multirow[t]{2}{*}{ elev } & & & & & $0.723^{* * *}$ & & 0.0724 \\
\hline & & & & & $(0.263)$ & & $(0.321)$ \\
\hline \multirow[t]{2}{*}{ shel } & & & & & & -0.326 & -0.254 \\
\hline & & & & & & $(0.318)$ & $(0.310)$ \\
\hline \multirow[t]{2}{*}{ _cons } & $14.23^{* * *}$ & $13.49^{* * *}$ & $13.44^{* * *}$ & $13.97^{* * *}$ & $14.61^{* * *}$ & $14.47^{* * *}$ & $14.21^{* * * *}$ \\
\hline & (2.018) & $(2.760)$ & $(3.206)$ & (1.954) & $(2.001)$ & $(2.031)$ & (1.985) \\
\hline$N$ & 305 & 148 & 157 & 305 & 305 & 305 & 305 \\
\hline$R^{2}$ & 0.264 & 0.313 & 0.280 & 0.313 & 0.283 & 0.267 & 0.315 \\
\hline
\end{tabular}

Standard errors in parentheses

$* p<0.10, * * p<0.05, * * * p<0.01$

Source: Authors' estimations from the Pam survey.

Table 4: Hypothetical Scenarios

\begin{tabular}{llccc}
\hline & & \multicolumn{2}{c}{ Total Loss and Damage (AUD\$) } \\
\cline { 3 - 5 } & & $\begin{array}{c}\text { Survey } \\
\text { Responses }\end{array}$ & $\begin{array}{c}\text { Outer } \\
\text { Islands } \\
\text { Total }\end{array}$ & $\begin{array}{c}\text { National } \\
\text { Total }\end{array}$ \\
\hline (i) & All household & $1,093,440$ & $1,796,497$ & $6,042,874$ \\
(ii) & Poor households only & 524,600 & 887,814 & $2,899,191$ \\
\hline
\end{tabular}

Note: Authors' calculations from survey and census data. 
Table 5: Hypothetical Scenarios

\begin{tabular}{|c|c|c|}
\hline & Scenario & $\begin{array}{l}\text { Loss and Damage as \% of } \\
\text { Loss of Poor Households (ii) }\end{array}$ \\
\hline 1 & Adjusted vulnerability, minimum income pc (poor households only) & 139.7 \\
\hline 2 & Adjusted vulnerability, mean income pc (poor households only) & 69.4 \\
\hline \multirow[t]{2}{*}{3} & Adjusted vulnerability maximum income pc (poor households only) & 19.9 \\
\hline & & $\begin{array}{l}\text { Loss and Damage as \% of } \\
\text { Loss of All Households (i) }\end{array}$ \\
\hline 4 & Adjusted vulnerability, all wooden houses & 143.1 \\
\hline 5 & Adjusted vulnerability, all cement houses & 91.7 \\
\hline 6 & Adjusted exposure, minimum distance to the coast & 150.1 \\
\hline 7 & Adjusted exposure, mean distance to the coast & 82.1 \\
\hline 8 & Adjusted exposure, maximum distance to the coast & 4.0 \\
\hline 9 & Adjusted exposure, minimum elevation & 192.5 \\
\hline 10 & Adjusted exposure, mean elevation & 87.3 \\
\hline 11 & Adjusted exposure, maximum elevation & 36.9 \\
\hline 12 & Adjusted exposure, minimum land width & 142.7 \\
\hline 13 & Adjusted exposure, mean land width & 106.7 \\
\hline 14 & Adjusted exposure, maximum land width & 48.1 \\
\hline 15 & Adjusted hazard, minimum distance to the cyclone path & 126.1 \\
\hline 16 & Adjusted hazard, mean distance to the cyclone path & 92.0 \\
\hline 17 & Adjusted hazard, maximum distance to the cyclone path & 27.9 \\
\hline 18 & Adjusted responsiveness, no one strengthened their houses & 140.1 \\
\hline 19 & Adjusted responsiveness, all strengthened their houses & 92.3 \\
\hline 20 & Adjusted responsiveness, no one received cyclone response training & 146.1 \\
\hline 21 & Adjusted responsiveness, all received cyclone response training & 83.7 \\
\hline 22 & Adjusted responsiveness, no one received an early warning & 119.1 \\
\hline 23 & Adjusted responsiveness, all received an early warning & 22.9 \\
\hline
\end{tabular}

Note: Authors' calculations from survey data and estimation results (table 3 columns 1-2). 


\section{Bibliography}

Akter, S., \& Mallick, B. (2013). The poverty-vulnerability-resilience nexus: Evidence from Bangladesh. Ecological Economics, 96, 114-124. https://doi.org/10.1016/j.ecolecon.2013.10.008

Briguglio, L. (1997). Small island developing states and their economic vulnerabilities. ScopeScientific Committee on Problems of the Environment: International Council Of Scientific Unions, 58, 210-215.

Briguglio, L., Cordina, G., Farrugia, N., \& Vella, S. (2009). Economic Vulnerability and Resilience: Concepts and Measurements. Oxford Development Studies, 37(3), 229247. https://doi.org/10.1080/13600810903089893

Cavallo, E., \& Noy, I. (2011). Natural Disasters and the Economy - A Survey. International Review of Environmental and Resource Economics, 5(1), 63-102. https://doi.org/10.1561/101.00000039

Christenson, E., Elliott, M., Banerjee, O., Hamrick, L., \& Bartram, J. (2014). Climate-Related Hazards: A Method for Global Assessment of Urban and Rural Population Exposure to Cyclones, Droughts, and Floods. International Journal of Environmental Research and Public Health, 11(2), 2169-2192. https://doi.org/10.3390/ijerph110202169

Clark, G. E., Moser, S. C., Ratick, S. J., Dow, K., Meyer, W. B., Emani, S., ... Schwarz, H. E. (1998). Assessing the vulnerability of coastal communities to extreme storms: the case of Revere, MA., USA. Mitigation and Adaptation Strategies for Global Change, 3(1), 59-82.

Cutter, S. L., Barnes, L., Berry, M., Burton, C., Evans, E., Tate, E., \& Webb, J. (2008). A placebased model for understanding community resilience to natural disasters. Global Environmental Change, 18(4), 598-606. https://doi.org/10.1016/j.gloenvcha.2008.07.013

ECLAC. (2014). Handbook for Disaster Assessment. Santiago, Chile: United Nations and Economic Commission for Latin America and the Caribbean (ECLAC).

Field, C. B., Barros, V. R., \& Intergovernmental Panel on Climate Change (Eds.). (2014). Climate change 2014: impacts, adaptation, and vulnerability: Working Group II contribution to the fifth assessment report of the Intergovernmental Panel on Climate Change. New York, NY: Cambridge University Press. 
Field, C. B., Barros, V. R., Mastrandrea, M. D., Mach, K. J., Abdrabo, M.-K., Adger, N., ... others. (2014). Summary for policymakers. Climate Change 2014: Impacts, Adaptation, and Vulnerability. Part A: Global and Sectoral Aspects. Contribution of Working Group II to the Fifth Assessment Report of the Intergovernmental Panel on Climate Change, 1-32.

Frankenberger, T., \& Nelson, S. (2013). Background Paper for the Expert Consultation on Resilience Measurement for Food Security. FAO \& WFP.

Gall, M. (2013). From social vulnerability to resilience measuring progress toward disaster risk reduction. Bonn: UNU-EHS.

Hallegatte, S. (2013). A cost effective solution to reduce disaster losses in developing countries: hydro-meteorological services, early warning, and evacuation. In B. Lomborg (Ed.), Global Problems, Smart Solutions (pp. 481-499). Cambridge: Cambridge University Press. Retrieved from http://ebooks.cambridge.org/ref/id/СBO9781139600484A019

Haughton, J., \& Khandker, S. (2009). Handbook on Poverty and Inequality. The World Bank. Retrieved from http://elibrary.worldbank.org/doi/book/10.1596/978-0-8213-7613-3

López-Marrero, T., \& Wisner, B. (2012). Not in the same boat: Disasters and differential vulnerability in the insular Caribbean. Caribbean Studies, 40(2), 129-168.

Mitchell, T., Jones, L., Lovell, E., \& Comba, E. (2013). Disaster Risk Management in Post-2015 Development Goals. London: Overseas Development Institute.

Noy, I. (2013). Fat tails and extreme disasters. In B. Lomborg (Ed.), Global Problems, Smart Solutions (pp. 439-509). Cambridge: Cambridge University Press. Retrieved from http://ebooks.cambridge.org/ref/id/CBO9781139600484A019

Noy, I. (2016). Natural disasters in the Pacific Island Countries: new measurements of impacts. Natural Hazards, 84(S1), 7-18. https://doi.org/10.1007/s11069-015-1957-6

Noy, I., \& Yonson, R. (2016). Economic Vulnerability and Resilience to Natural Hazards. Oxford Research Encylopedia of Natural Hazard Science. https://doi.org/10.1093/acrefore/9780199389407.013.76

Schumacher, I., \& Strobl, E. (2011). Economic development and losses due to natural disasters: The role of hazard exposure. Ecological Economics, 72, 97-105. https://doi.org/10.1016/j.ecolecon.2011.09.002 
Smith, R.-A. J., \& Rhiney, K. (2015). Climate (in)justice, vulnerability and livelihoods in the Caribbean: The case of the indigenous Caribs in northeastern St. Vincent. Geoforum. https://doi.org/10.1016/j.geoforum.2015.11.008

Strobl, E. (2012). The economic growth impact of natural disasters in developing countries: Evidence from hurricane strikes in the Central American and Caribbean regions. Journal of Development Economics, 97(1), 130-141. https://doi.org/10.1016/j.jdeveco.2010.12.002

Taupo, T., Cuffe, H., \& Noy, I. (2016). Household vulnerability on the frontline of climate change: The Pacific atoll nation of Tuvalu. Retrieved from http://www.victoria.ac.nz/sef/research/pdf/SEF-Working-Paper-20-2016.pdf

Tuvalu Government. (2015). Rapid Assessment Report on Cyclone Pam for Tuvalu. Funafuti: Tuvalu Government.

UNDP. (2013). Community Based Resilience Assessment (CoBRA) Conceptual Framework and Methodology.pdf. UNDP Drylands Development Center.

UNISDR. (2009). UNISDR Terminology on Disaster Risk Reduction. Geneva, Switzerland: United Nations International Strategy for Disaster Reduction.

United Nations. (2015). 2015 Global Assessment Report on Disaster Risk Reduction. New York: United Nations Office for Disaster Risk Reduction.

United Nations Office for the Coordination of Humanitarian Affairs. (2015). Tuvalu: Tropical Pam Situation Report No.1. United Nations.

Winderl, T. (2014). Disaster Resilience Measurements. United Nations Development Programme.

Wisner, B., Blaikie, P., Cannon, T., \& Davis, I. (2003). At Risk: natural hazards, people's vulnerability and disasters (2nd Edition). New York: Routledge.

Wisner, B., Gaillard, J. C., \& Kelman, I. (2011). Framing disaster. Retrieved from https://www.routledgehandbooks.com/doi/10.4324/9780203844236.ch3

World Bank. (2014). Hardship and Vulnerability in the Pacific Island Countries. Washington D.C: The World Bank.

World Bank, \& GFDRR. (2013). Building Resilience. The World Bank.

Yonson, R., Gaillard, J. C., \& Noy, I. (2016). The measurement of disaster risk: An example from tropical cyclones in the Philippines. Retrieved from http://researcharchive.vuw.ac.nz/handle/10063/4979 


\section{Appendix A: Loss and Damage \& Scenario Maps}

Appendix Figure 1: Hypothetical Scenarios for Nui Island

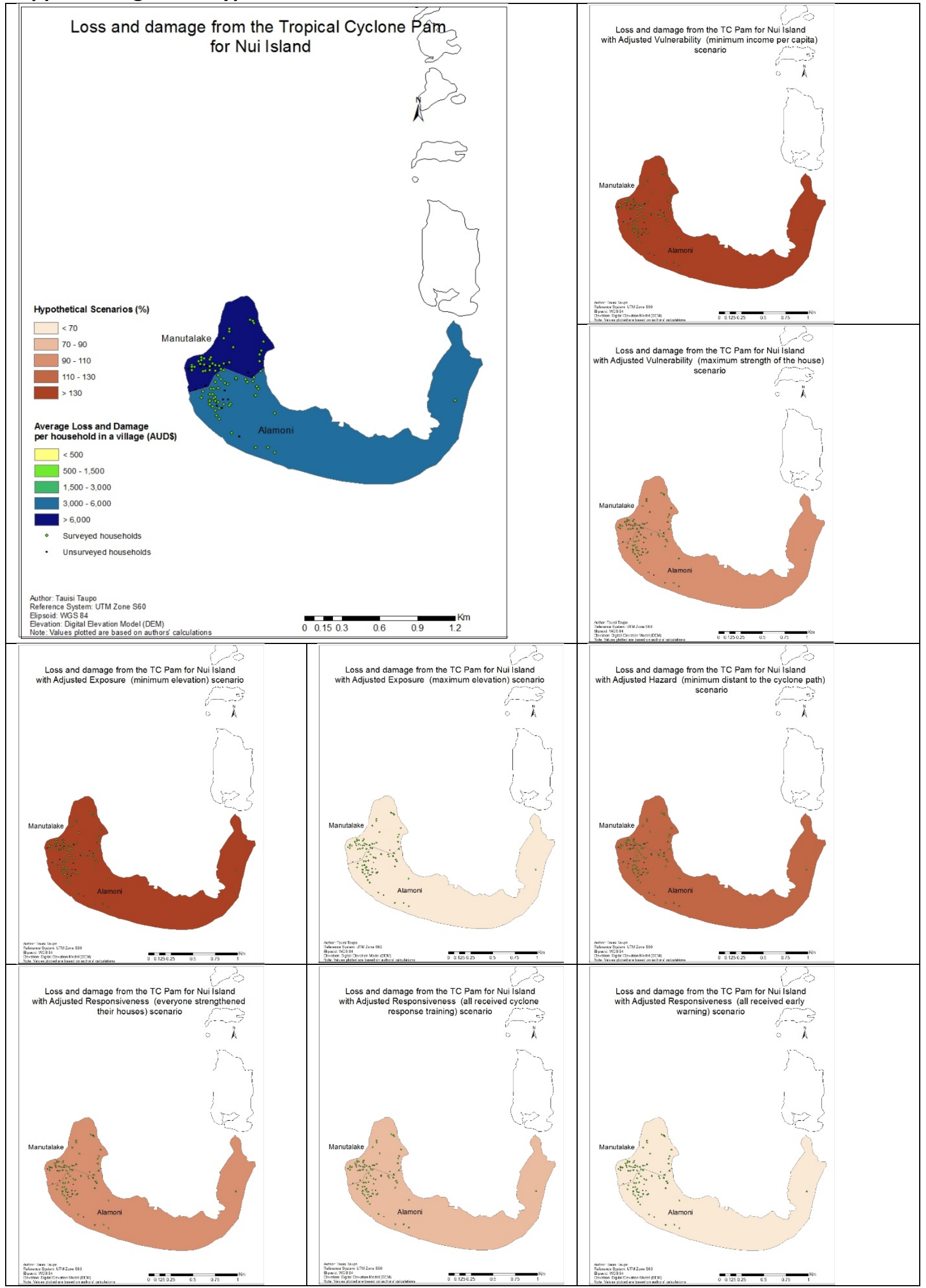

Source: Authors' digitized maps. 
Appendix Figure 2: Loss and Damage For Nanumea, Nanumaga, Niutao and Nukulaelae

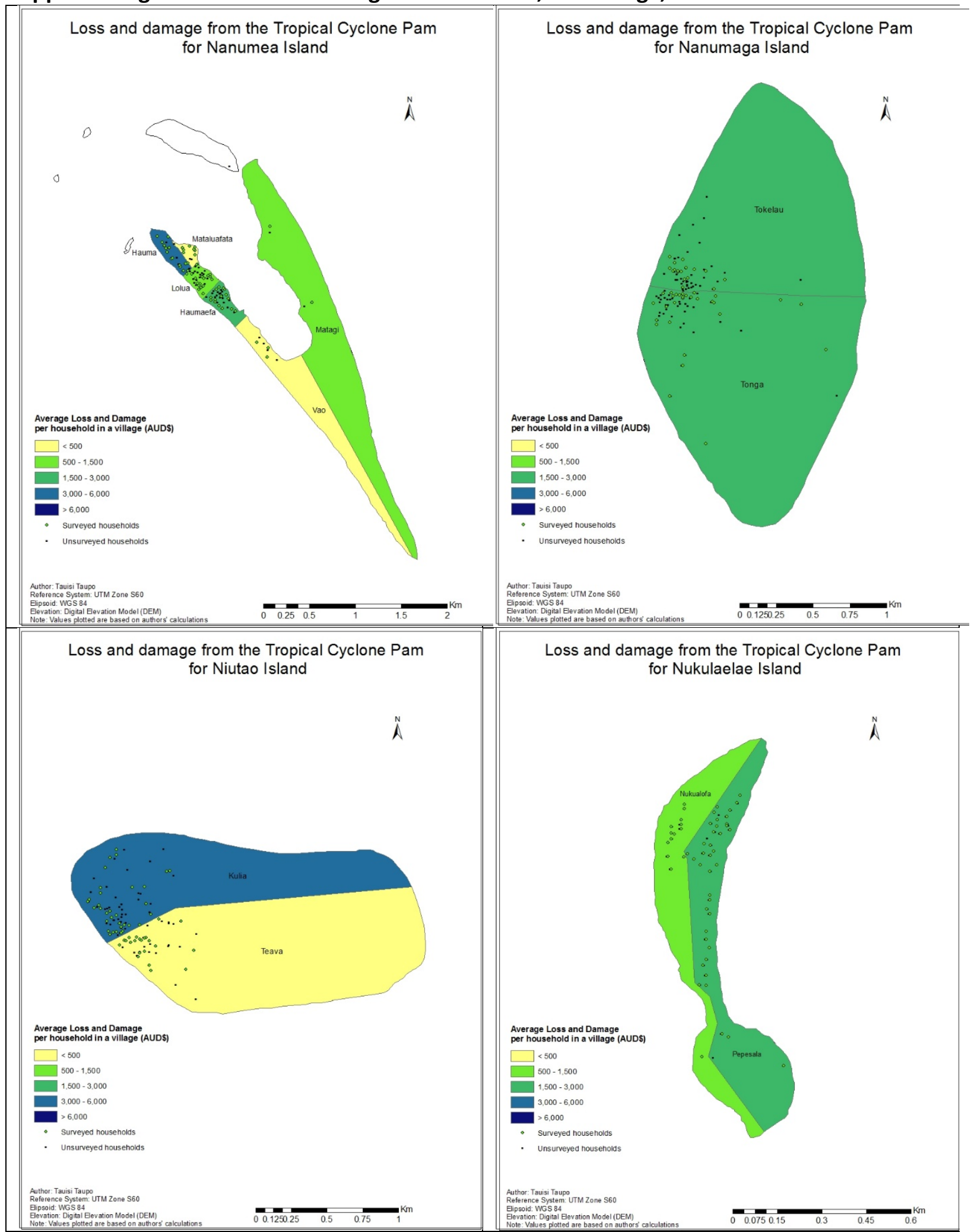

Source: Authors' digitized maps. 


\section{ENDNOTES}

We are indebted to all interviewers for carrying out the field work in Tuvalu, and the Tuvalu Central Statistics Office for their valuable inputs and immense support. Taupo also acknowledges the financial support of the NZAID. We gratefully acknowledge inputs and feedback from participants and reviewers of the 2016 New Zealand Association of Economists conference (Auckland), the 2016 Pacific Update conference (Suva, Fiji), and the 2016 International Conference on Building Resilience (Auckland).

${ }^{1}$ In terms of lowest maximum elevation, Tuvalu is the second lowest-elevation country in the world after the Maldives.

${ }^{2}$ This figure is proportionally twice as large as the damage experienced in Japan from the 2011 triple earthquake-tsunami-nuclear accident catastrophe.

${ }^{3}$ The Atoll nations are Tuvalu, Kiribati, Nauru, Marshall Islands (in the Pacific) and the Maldives (in the Indian Ocean). There are other populated atoll islands in other countries in the Pacific and elsewhere.

${ }^{4}$ Examples include Clark et al. (1998) which stresses that the two functions of vulnerability are exposure and coping ability. This coping ability is partitioned in their analysis into resistance and resilience. According to Briguglio et al. (2009), risk is determine by exposure and coping ability that are associated with vulnerability and resilience, respectively. Cutter et al. (2008) discusses a framework called the Disaster Resilience of Place (DROP) model which explains and articulates the relationship between vulnerability, resilience and adaptive capacity. However, they defined vulnerability and resilience as the inherent characteristics that create the potential for harm, and the ability to respond and recover from disasters, respectively. There are multiple other frameworks, including many works that emphasized the root causes of vulnerability and the role of poverty in these dynamics; work that is frequently associated with Wisner and his co-authors (e.g., Wisner, Blaikie, Cannon, \& Davis, 2003). See Noy and Rio (2016) for a survey of the relevant concepts and their measurement.

${ }^{5}$ There are many other recent studies and discussions on resilience (Frankenberger \& Nelson, 2013; Gall, 2013; Mitchell, Jones, Lovell, \& Comba, 2013; UNDP, 2013).

${ }^{6}$ The full questionnaire is available for download at: https://sites.google.com/site/noyeconomics/research/natural-disasters.

${ }^{7}$ We used a systematic random sampling approach where we calculated a skip interval before randomly selecting a starting point from a list of households made available to us from the Central Statistical Division. We then count down and skip by the number of the skip interval until we obtained our desired sample size. The survey questionnaire was approved by the Victoria University of Wellington's Ethics Committee before the survey was conducted. We encountered some difficulties during the period of the survey around December 2015 as Tuvalu was hit by gale winds from Cyclone Ula, preventing ships from going to the outer-islands for almost a week, but luckily the survey was finally completed. The results presented here were weighted using methods employed by the Central Statistics Division Tuvalu to represent the population of the households.

${ }^{8}$ The survey was conducted using trained interviewers, trained and supervised by one of the authors.

${ }^{9}$ The consumption bundle of adequate food and non-food estimates a poverty line that is seen as a reasonable minimum expenditure required to satisfy both basic food and non-food needs. We used an estimated food consumption expenditure required for daily calorie energy intake per person that is parallel with the FAO requirement of 2100 kilocalories (Kcal). This measure is consistent with the official poverty measure used by the Government of Tuvalu. More details regarding poverty measures in Tuvalu are available from Taupo, Cuffe \& Noy (2016)

${ }^{10}$ We gathered price lists of building materials and furniture from hardware outlets in the capital. We used market prices for estimating equipment values.

${ }^{11}$ These estimated cost of houses, local kitchens, outdoor toilets, water tanks and others were gathered from the Public Works Department (PWD), while the 2015 prices of building materials were collected from the Central Statistics Division and quotations from the 3 main hardware stores (JY Ltd, McKenzie Ltd and Messamesui Ltd) on Funafuti.

${ }^{12}$ The same principles were also applied for losses, by tagging a value on an item that is being lost or destroyed, using local market prices to determine their values. If two pigs died as a consequence of the cyclone, then we used a value of AUD 200 if they both weigh $20 \mathrm{~kg}$ at a local price of AUD 10 per $\mathrm{kg}$. We used a similar procedure for crops and plants. Local market prices for 2015 were gathered from the Central Statistics Division. Unlike crops and plants that have a shorter lifespan and are harvested and new ones are replanted again in their places, fruit trees provide fruits for a longer period. Valuing their loss is therefore more complex. The only information that was collected is the number of fruit trees and their expected lifetime left in years. 
For consistency across households, the acquired information together with the local market prices of the fruits were used to calculate the values of fruit trees that were lost.

${ }^{13}$ Poultry (chickens and ducks) was excluded in the calculations of losses since they are mostly left in the open. Unlike pigs, they are easily accounted as they are well kept in pigsties.

${ }^{14}$ Based on the latest GDP figure of AUD 41.2 million in the Government of Tuvalu 2015 National Budget.

${ }^{15}$ This include damages to households, community halls, community water storages, seawalls, clinics, beach ramps, roads, telecommunication wiring pits, electricity meter boxes, etc. (Tuvalu Government, 2015; United Nations Office for the Coordination of Humanitarian Affairs, 2015).

${ }^{16}$ Residents of Nukufetau only experienced damage to water storage facilities due to the intrusion of sea water into water storage tanks; and the crops on Nukufetau were mostly destroyed since they are located on a western islet that was directly exposed to the cyclone-generated surges.

17 The prevailing winds are easterlies. In islands without lagoons, populations tend to concentrate on the western side of the island (away from the wind), while on islands with lagoons, populations tend to reside on the lagoon side.

${ }^{18}$ Information calculated from the 1991 and 2012 Censuses.

${ }^{19}$ The conversion rate of 1USD Dollar (US Dollar) = 1.33AUD Dollar (Australian Dollar) was used throughout.

${ }^{20}$ In the 2012 Census, $80 \%$ of households reported having access to NBT, the only bank operating in Tuvalu.

${ }^{21}$ This observation is based on conversations with AirWorldwide, the modeler for the Pacific Catastrophe Risk Assessment and Insurance (PCRAFI) program. We suspect this is the case for other natural hazard risk modelers such as RMS.

${ }^{22}$ Though we cannot rule out the possibility that the availability of early warning is somehow endogenously determined.

${ }^{23}$ The World Bank (2015) estimated Tuvalu's GDP at AUD 41.7 million, so that total loss and damage to households was about $4.6 \%$ of GDP. 